\title{
Prevalence and Social Determinants of Type 2 Diabetes in a Coastal Area of Kerala, India
}

\author{
Aswathy $S^{1^{*}}$, Lohidas V ${ }^{1}$, Nimitha Paul ${ }^{2}$, Anish $\mathrm{TS}^{3}$, Tinu Narayanan ${ }^{3}$ and Brian \\ Oldenburg ${ }^{4}$ \\ ${ }^{1}$ Professor, Dept of Community Medicine, Amrita Institute of Medical sciences, Amrita University, Kochi, \\ Kerala, India \\ ${ }^{2}$ Lecturer in Biostatistics, Dept of Community Medicine, Amrita Institute of Medical sciences, Amrita \\ University, Kochi, Kerala, India \\ ${ }^{3}$ Social Worker, Dept of Community Medicine, Amrita Community Health Training Centre, Njarakkal, \\ AmritaUniversity, Kochi, Kerala, India \\ ${ }^{4}$ Professor, Chair of Non-Communicable Disease Control \&Director of the Centre for Health Equity, \\ Melbourne School of Population and Global Health, University of Melbourne, Australia.
}

Received: August 05, 2017; Accepted: August 20, 2017; Published: September 15, 2017

*Corresponding author: Dr. Aswathy S, Professor, Community Medicine, Amrita Institute of Medical sciences, Amrita University, Kochi, Kerala, India Tel: +91 9447294260; Fax: 0484 2801020;E-mail: aswathys@aims.amrita.edu

\begin{abstract}
Introduction

Varying prevalence rates of type 2 diabetes have been observed in different parts of the southern state of Kerala, India which is in an advanced stage of epidemiologic transition. Social patterning is evident in diabetes and therefore it was decided to undertake a study on estimating the prevalence of diabetes and associated social determinants.
\end{abstract}

\section{Methodology}

The adopted local self administration unit of the Medical College which is also the field practice area with a population of 25,096 was taken for the study. All the households in the area were visited and the details regarding self reported diabetes was collected after obtaining informed consent and analysis done by multivariate logistic regression.

Result

The prevalence of self reported diabetes in this coastal area was found to be low at 7.4\%.Type 2 diabetes was also found to occur significantly earlier among the respondents belonging to the below poverty line. Age above 40 years(OR2 95\%CI 1.5-2.7,p=.000),marital status(OR1.9 95\%CI 1.1-2.1,p=.006)presence of comorbidities(OR635 95\%CI 389-969,p=.000),more than 8 years of schooling(OR 0.64 95\%CI 0.46-0.86,p=.004),living conditions as represented by presence of household source of drinking water(OR 1.4 95\% CI 1.01-1.5) were found to be independent predictors. Though there was increasing trend of diabetes among the forward caste line families after backward logistic regression this disappeared leaving behind the proxy of socioeconomic status, household source of drinking water.

\section{Conclusion}

Though, the state of Kerala is in an advanced stage of epidemiologic transition, coastal areas are still in the earlier phases of transition with low prevalence of type 2 diabetes mellitus. Higher education and better living conditions are important social determinants of diabetes though further studies are necessary to delineate the impact of economic status and education.

\section{Keywords}

Social Determinants; Type2 Diabetes; Coastal Areas

\section{Introduction}

Type 2 diabetes is a complex and demanding chronic condition resulting from the body's inability to adequately produce and or effectively utilize insulin Genetics and lifestyle behaviours are implicated in the pathogenesis [1-3]. Kerala, a state in the southern part of India with a prevalence of type 2 diabetes of $20 \%$ leads the country in epidemiologic transition and is a harbinger of what will happen in the rest of India [4,5].Varying prevalence rates have been reported from various geographic regions of the state such as coastal, midland, highland, central part of the state indicating that it is not uniformly high throughout the state $[6,7]$. 
Lifestyle factors are strongly patterned by socioeconomic status [8]. The latency model emphasizes that psychosocial and socio-economic conditions vary early in life and will have a strong impact later in life independent of intervening experience [9]. The landmark UK White hall studies pointed out that $90 \%$ of variance in occurrence of metabolic syndrome cannot be accounted for by conventional behavioural risk factors [10].The Commission on Social determinants of diabetes in 2008 also reported that the true upstream drivers of health inequities reside in the social, economic and political environments [11]. As we consider improving diabetes outcomes, social determinants of health and diabetes need consideration [12].

In cardiovascular disease(CVD), of which diabetes is a major cause the epidemic struck the more affluent sections of India first, but with the maturing epidemic a reversal of social gradient has been observed with socio-economically disadvantaged groups becoming increasingly vulnerable to CVD [13]. However, not all children and adults living in low socio-economic circumstances have poor health; they are more likely to develop poor physical and emotional outcomes than those living in better circumstances [13].

Studies in Kerala have shown a low prevalence in coastal area and it has been suggested that the prevalence of type 2 diabetes and other cardiovascular risk factors may increasingly be concentrated in the lower socioeconomic groups though cross sectional multilevel analysis based on National family Health survey3 data across India indicates otherwise[5,14]. There is strong social patterning in the incidence of type 2 diabetes and therefore it was decided to look into the prevalence and social determinants of diabetes in a coastal area with high population density in a state in an advanced stage of epidemiologic transition [15].

\section{Methods}

A cross sectional study was carried out in the local self government area adopted by the Dept of Community Medicine of the School of Medicine in the period 2009-2010.This is also a block where unemployment is high[16].The density of population in this island which is also a revenue block is the highest in Asia[16]. All the adult members (above 18 years) in the local self government area were considered for the study. Thus a total of 14036 adults were interviewed in house to house visits by trained data collectors using a semi structured questionnaire which was pretested and then necessary additions made. Written informed consent was obtained from the householders. The questionnaire was part of a schedule to collect baseline characteristics of the population. Self reported diabetes was considered for study purposes. Locked houses were excluded from the study after two visits. The primary outcome variable was self reported diabetes status. The social determinants included socioeconomic status, education, caste, gender, living conditions as determined by access to water and availability of toilet. Other than social determinants co morbidities and personal habits were also studied. Socioeconomic status was determined by a 9 point poverty scale index developed by Government of Kerala as part of its poverty eradication mission [17].The socioeconomic status was also assessed with the help of ration card, according to which families are categorised into Above poverty Line (APL), Below poverty line (BPL).The BPL card holders are eligible for various social assistance schemes through the public distribution system.

\section{Results}

The prevalence of self reported type 2 diabetes in this coastal self administration unit (panchayat) of Ernakulam District was found to be $7.4 \%$ ( $95 \%$ CI 6.98 to 7.84 ) among adults.

The mean age of the population was $42.7(16.03)$ yrs with male and females almost equally distributed at $48.9 \%$ and $51 \%$ respectively. Among the study population the most vulnerable and marginalised group-Scheduled Caste and Scheduled tribe [18] consisted of $17 \%$.Nearly a half (48.16\%) consisted of other backward castes and other eligible communities and only a third (34.75\%) belonged to the socioculturally cum economically forward group. The socioeconomic status as determined by the point poverty index indicated that $7.4 \%$ were poor or at risk of poverty whereas according to the ration card which is the determinant of identity, eligibility and entitlement to the public distribution system, less than a third (30.02\%)were BPL,5.4\% had no cards and the rest were APL. The higher level of BPL may be due to underreporting of income data due to availability of many social assistance measures and the point poverty index indicates the poorest of the poor. As far as living conditions in terms of access to water was concerned only $22.8 \%$ had access to a house connection. In this water scarce area a majority of the population $(67.8 \%)$ were using water from a public tap. Toilet facilities indicated that $82.2 \%$ had a proper toilet and $7.9 \%$ had toilets which drained into the canals which in turn drained into the sea.

The age range of the population affected by diabetes varied from 22 to 90 years with a mean age of 59.28(11.89) years higher than the study population mean of $42.7(16.03)$. A marginally higher prevalence of type 2 diabetes was found among women at $7.8 \%$ (95\% CI6.9 to 8.2), though the gender difference is not statistically significant. Correspondingly, women constituted a slightly larger proportion $53.9 \%$ among diabetes as compared to $51.03 \%$ among the study population. The prevalence of Diabetes increased with increasing age though the peak prevalence was

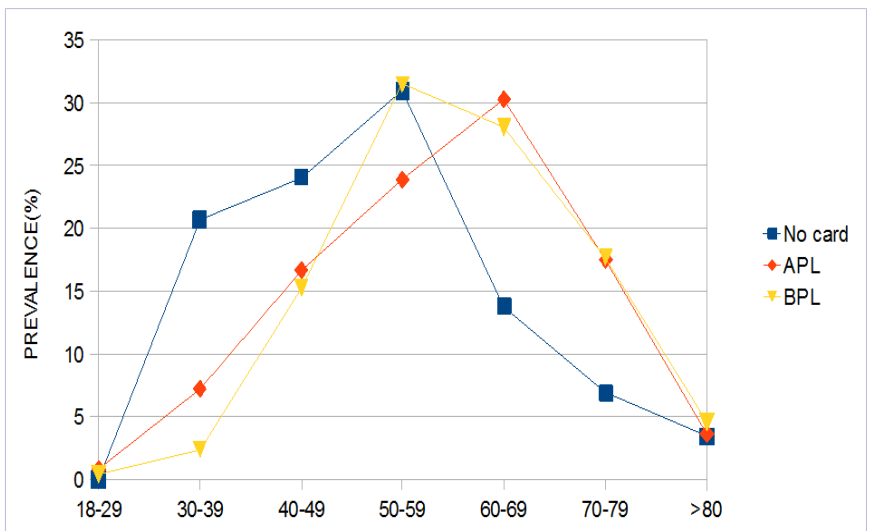

Figure 1: Age distribution of the persons with diabetes according to Socioeconomic status 
in a significantly younger age at 50-59 years in the BPL(below poverty line) group and no card group compared to 60-69 years in the APL(above poverty line) group $(\mathrm{p}<0.008)$. The no card group indicates people who have recently migrated into the area and have no ration cards and are a vulnerable (Figure 1).

The factors significantly associated with the prevalence of Diabetes were age $>40$ yrs, (OR 16.6,95\% CI 13.4-22.3),married(OR10.35,95\%CI 7.1-15.3), addictive habits like ever smokers and ever alcoholics were (OR1.2, CI 0.9-1.4; OR1.4 95\% CI 1.1-1.7,p=.05 ), presence of comorbidities(OR820 95\%CI 389.3-1727.1,p=.000)was significantly more likely among the diabetics. The types of comorbidities that were present included hypertension, hypercholesterolemia heart disease, stroke etc. People with a house connection of water supply were found to be 2.2 times prone to have Diabetes(OR 2.3, 95\% CI1.5$3.8, p<.001$ ) and a gradient was observed from public tap to well and borewell to home connection indicating that this was also a proxy for economic status. With regard to toilet facilities too a significant gradient was observed with the highest levels (OR1.7, 95\% CI1.3-1.9) among those with proper toilet followed by (OR 1.3, 95\% CI0.9-1.5) among those with an improper toilet in comparison to those without toilet. Thus both of these indicators of living conditions seem to serve as a proxy for economic status as well, with increasing prevalence among the higher socioeconomic status. This trend was also reflected in education where with increasing education an increase in prevalence was observed. (Table 1)

\begin{tabular}{|c|c|c|c|c|c|}
\hline & & $\mathrm{DM}(\%)$ & Total & OR(95\% CI) & $\mathbf{P}$ \\
\hline \multirow{2}{*}{ Age } & $<40$ yrs & $69(.97)$ & 7112 & 1 & \multirow{2}{*}{$<0.001$} \\
\hline & $>40 y r s$ & 969(13.9) & 6924 & $16.6(13.4,22.3)$ & \\
\hline \multirow{2}{*}{ Sex } & Male & $479(6.9)$ & 6873 & 1 & \multirow{2}{*}{0.059} \\
\hline & Female & $559(7.8)$ & 7163 & $1.13(.78,1.8)$ & \\
\hline \multirow{2}{*}{ Marital status } & Never married & $27(.9)$ & 2843 & 1 & \multirow{2}{*}{$<0.001$} \\
\hline & Ever married & $1011(9)$ & 11193 & $10.35(7.1,15.3)$ & \\
\hline \multirow{2}{*}{$\begin{array}{c}\text { Poor } \\
\text { (according to point } \\
\text { poverty index) }\end{array}$} & No & $976(7.5 \%)$ & 12996 & 1 & \multirow{2}{*}{0.06} \\
\hline & Yes & $62(5.9 \%)$ & 1040 & $0.78(.599,1.017)$ & \\
\hline \multirow{3}{*}{ Ration card status } & BPL & $251(6 \%)$ & 4215 & 1 & \\
\hline & No card & $29(3.8 \%)$ & 766 & $0.4(.29,1.23)$ & 0.43 \\
\hline & APL & $758(8.4 \%)$ & 9055 & $0.7(0.59,1.12)$ & 0.62 \\
\hline \multirow{3}{*}{ Caste } & SC\&ST & $172(7.1)$ & 2398 & 1 & \\
\hline & OBC\&OEC & $467(6.9)$ & 6760 & $0.96(0.84,1.8)$ & 0.66 \\
\hline & Others & $399(8.1)$ & 4878 & $1.15(1.01,3.4)$ & 0.13 \\
\hline \multirow{4}{*}{ Education } & Illiterate & $55(12.7)$ & 431 & 1 & \\
\hline & Upto 7 yrs of schooling & $447(11.3)$ & 3924 & $.713(0.6,0.9)$ & $<0.001$ \\
\hline & $8-12$ yrs of schooling & $452(6.1)$ & 7344 & $27.7 .4(15.3,40.12)$ & 0.004 \\
\hline & $>12$ yrs of schooling & $84(3.5)$ & 2337 & 56.29. $(35.12,65.17)$ & 0.003 \\
\hline \multirow{4}{*}{ Addictive habits } & No habit & 890 & 12362 & 1 & \\
\hline & Ever smoker & 33 & 368 & $1.2(0.9,1.4)$ & 0.58 \\
\hline & Ever alcoholic & 52 & 516 & $1.4(1.1,1.7)$ & 0.05 \\
\hline & $\begin{array}{l}\text { Ever smoking and } \\
\text { drinking }\end{array}$ & 63 & 790 & $1.1(0.8,1.3)$ & 0.538 \\
\hline \multirow[b]{2}{*}{ Co morbidities } & Absent & 7 & 11026 & 1 & \multirow[b]{2}{*}{$<0.001$} \\
\hline & Present & 1031 & 3010 & $\begin{array}{c}820 \\
(389.3,1727.1)\end{array}$ & \\
\hline \multicolumn{6}{|l|}{ Living conditions } \\
\hline \multirow{3}{*}{ Toilet facilities } & None & $65(4.7)$ & 1376 & 1 & \\
\hline & Inappropriate & $70(6.2)$ & 1112 & $1.3(0.9,1.5)$ & 0.58 \\
\hline & Appropriate & $903(7.8)$ & 11548 & 1.7(1.3-1.9) & $<0.001$ \\
\hline \multirow{4}{*}{ Water source } & Public tap & $605(6.4)$ & 9524 & 1 & \\
\hline & Home connection & $337(10.6)$ & 3183 & $1.74(1.5-3.8)$ & $<0.001$ \\
\hline & Well \&bore well & $67(9)$ & 748 & $1.45(1.24,3.68)$ & 0.006 \\
\hline & Rainwater & $29(5)$ & 581 & $.77(.689,1.23)$ & 0.19 \\
\hline
\end{tabular}

Citation: Aswathy S, Lohidas V, et al. (2017)Prevalence and Social Determinants of Type 2 Diabetes in a Coastal Area of Kerala, India. Page 3 of 5 J Endocrinol Diab 4(3):1-5. DOI: http://dx.doi.org/10.15226/2374-6890/4/3/00181 
All factors with $\mathrm{p}$ value $<0.2$ in univariate analysis were included in binary logistic regression model to find the independent predictors of diabetes using backward conditional method. The final model showed that age $>40$ yrs(OR2 95\%CI 1.5-2.7,p=.000),married(OR 1.9 95\%CI 1.12-2.1,p=.006) ,8-12 yrs of schooling and more than $12 \mathrm{yrs}$ of schooling (OR 1.63 95\%CI 1.23-2.14,p=.006; OR $1.80 \quad 95 \% \mathrm{CI} \quad 1.22-2.40, \mathrm{p}=.014)$ ), having co morbidities (OR635 95\%CI 389-969,p=.000) and living conditions represented by house connection for water supply (OR 1.4 95\%CI 1.01-1.47,p=.001) were independent predictors of diabetes. (Table 2) On the whole it appeared that it was the better off people who were more affected with diabetes as is the case in the early phases of the epidemic in developing countries. Though Kerala in general is experiencing later stages of the epidemic, this study shows that it is not uniformly so.

Table 2: Independent predictors of type 2 diabetes

\begin{tabular}{|c|c|c|c|}
\hline Age(in years) & OR & $95 \%$ CI & $\mathbf{p}$ \\
\hline$>40$ & 2.1 & $1.54-2.77$ & 0.001 \\
\hline \multicolumn{4}{|l|}{ Marital status } \\
\hline Ever Married & 1.86 & $1.12-2.1$ & 0.006 \\
\hline Comorbidities Present & 635 & $389-1727.1$ & $<0.001$ \\
\hline Water source Home connection & 1.4 & $1.01-1.2$ & 0.001 \\
\hline \multicolumn{4}{|l|}{ Education } \\
\hline $8-12 y r s$ & 1.63 & $1.23-2.14$ & 0.004 \\
\hline$>12$ yrs & 1.8 & $1.22-2.4$ & 0.014 \\
\hline
\end{tabular}

\section{Discussion}

A low prevalence of $7.4 \%$ was found in this coastal population in the southern state of India. A decade earlier Kutty et al. [6] observed that the prevalence of diabetes in the southernmost state of India shows differences with geographical areas with low levels $(2.7 \%)$ in coastal areas. The Amritha Diabetes and Endocrine population survey(ADEPS) in the same district in an urban area in 2005 identified 9\% reported prevalence and $10.5 \%$ new cases of diabetes [4].The prevalence in central kerala in 2007 was 14.6\% [7]. A nationwide Non Communicable Disease risk factor surveillance study a few years before this showed the prevalence of self reported diabetes to be higher in urban, intermediate in periurban and lowest in rural areas[19]. Gender differences showed a marginally higher prevalence among women and this was so in the studies in coastal region in contrast to rural parts of central Kerala which has shown higher prevalence among men[6,7].Age more than or equal to 40 years was an independent predictor of type 2 diabetes. The country wide risk factor surveillance also showed a significant increase in self reported Diabetes with increasing age across rural, perurban and urban areas [19]. In line with increasing age married persons was also found to be an independent predictor of self reported diabetes.
The country wide risk factor surveillance study done in the four geographic regions of India found an OR of 3(95\%CI1.72.7) for those with graduate level education compared to those with no formal schooling [19]. In a study based on the NFHS 3(national Family health survey3 2005-2006) which determined the association between socioeconomic status and self reported diabetes where socioeconomic status was compositely determined by estimating household wealth, education and social caste, an increasing prevalence of diabetes with increasing education was observed [14]. In the same study fully adjusted model household wealth was as a significant factor reported consistently across India for self reported diabetes. In this study a significantly higher prevalence of diabetes has been observed among those with 8-12 yrs of schooling and more than 12 years of schooling similar to other studies [14, 17]. There was increasing prevalence of diabetes across the socioeconomic strata as represented by the ration card possessed, such as $3.8 \%$ in the no card holders, $6 \%$ among the below poverty line (BPL) card holders to $8.4 \%$ in the above poverty line (APL) card holders though this was not significant. Therefore the point poverty index was also taken into account and this also showed a similar picture with the at risk (poor) families having lower prevalence of diabetes at $5.9 \%$ compared to $7.5 \%$ among those not at risk, though not significant. Complex factors in the physical and social environment affect health [20]. Reflective of the socioeconomic status were the access to own household connection of tap water. In the unadjusted analysis a gradient was observed in the analysis with increasing OR from those using a public tap to those having their own home connection. In the adjusted analysis it has been observed that it is the people with own home connection that have higher rates of prevalence of diabetes.

Those with comorbidities such as hypertension, hypercholesterolemia were found to be an independent predictor of a higher prevalence of diabetes. Similar findings from other parts of Kerala indicate that the co existence of other non communicable diseases amplified the burden of diabetes mellitus with a higher association of diseases like hypercholesterolemia, hypertension and obesity [7].

The limitations of this study are that only self reported diabetes was considered which could be an underestimate of the problem. Though, previous research indicates that there is good agreement between self reported diabetes and medical records in a US population and in India self reported health conditions and social determinants like socioeconomic status have an expected relationship [21,22].

Though Kerala is in an advanced stage of epidemiologic transition, it appears that there are some areas which are still in the earlier phases of transition. Thus; the prevalence of diabetes in this coastal area was low at 7.4\%. type 2 diabetes has been found to occur at an earlier age among the poorer people. The overall picture seems to indicate the prevalence of the disease among the well to do as indicated by living conditions and educational status where those with at least 8 years of schooling had a higher risk. However, the study all over India also showed household wealth was the strongest socioeconomic factor suggesting that social 
and behavioural factors such as sedentariness and increased consumption of calories associated with diabetes in India may be more closely related to increasing wealth than educational status $[7,14]$. In contrast, in western society's voluntary leisure time physical activity and a healthier lifestyle are more common among the affluent [23]. Economic status and or education are important social determinants though further studies are necessary to delineate the impact of the two factors differentially or cumulatively.

\section{Conclusion}

Though, the state of Kerala is in an advanced stage of epidemiologic transition, it appears that coastal areas are in the earlier phases of transition with low prevalence of type 2 diabetes mellitus. Higher education and better living conditions are important social determinants of diabetes though further studies are necessary to delineate the impact of economic status and education differentially or cumulatively.

\section{Acknowledgement}

The authors acknowledge the support of Mr. K. Kumarankutty, Ms Devaki K and Ms. Radhika .S for data collection. AS was supported by the Fogarty International Centre, National Institutes of Health, under Award Number: D43Tw008332 (ASCEND Research Network).The contents of this article is solely the responsibility of the author and does not necessarily represent the official views of the National Institutes of Health or the ASCEND . Program.

\section{References}

1. Raphael D. Type 2 Diabetes: Poverty, Priorities and policy. The social determinants of the incidence and management of type 2 diabetes. 2017.

2. Aswathy S, Unnikrishnan AG, Sundaram KR, Leelamoni K. A Randomized controlled trial of the effect of yoga and peer support on glycaemic outcomes in women with type 2 diabetes mellitus: a feasibility study. BMC Complement Altern Med. 2017;17(1):100. Doi 10.1186/s12906-017-1574-x

3. Zimmet P, Alberti KGMM, Jonathan S. Global and societal implications of the diabetes epidemic. Nature. 2001;414:782-787. Doi: $10.1038 / 414782 a$

4. Menon VU, Kumar K, Allison G, Sugathan N, Sundaram KR, Vasantha N et al. Prevalence of known and undetected diabetes and associated risk factors in central Kerala, ADEPS. Diab Res Clin pract. 2006;74(3):289294. Doi: 10.1016/j.diabres.2006.03.025

5. Thankappan KR, Shah B, Mathur P, Sarma PS, Srinivas G, Mini GK, et al. Risk factor profile for chronic non-communicable diseases: results of a community-based study in Kerala, India. Indian J Med Res. 2010;131:53-63.

6. Ramankutty V, Soman CR, Joseph A, Pisharody R, Vijayakumar K. Type 2 diabetes in southern Kerala: Variation in prevalence among geographic divisions within a region. The National Medical Journal of India. 2000;13(6):287-292.
7. Vijayakumar G, Arun R, Kutty VR. High prevalence of type 2 diabetes mellitus and other metabolic disorders in rural central kerala. JAPI. 2009;57:563-567.

8. Adler NE, Newman K. Socioeconomic disparities in health: pathways and policies. HealthAff (Milwood). 2002;21(2):60-76.

9. Power C, Hertzman C. Social and biological pathways linking early life and adult disease. Br Med Bull. 1997;53(1):210-221.

10. Marmot M, Wilinson RG .Social determinants of health. Oxford; Oxford University Press:1999.

11. Commission on Social determinants of health: WHO.

12. Myra LC, Sharon WU. Social determinants of type 2 diabetes and health in the United States. World J of Diabetes. 2014;5(3):296-304. Doi: 10.4239/wjd.v5.i3.296

13.Jeemon P, Reddy KS. Social determinants of cardiovascular disease outcomes in Indians. Indian J Med Res. 2010;132(5):617-622. Doi: 10.4103/0971-5916.73415

14. Corsi DJ, Subramaniam SV. Association between socioeconomic status and self reported diabetes in India:a cross section multilevel analysis. BMJ Open.2012;2(4):e000895.

15. Whiting D, Unwin N, Roglic G. Diabetes: equity and socialdeterminants. In Blas E, Kurup A, editors, Equity, socialdeterminants and public health programmes, World Health Organization. 2010;:77-94.

16. Chatturvedi JC. Political Governance: Public policy and administration Gyan Publishing house; Facsimile Publisher;2005.

17. Report of the task force on poverty elimination. Govt of Kerala, State Planning Board, Thiruvananthapuram. 2015.

18. Chitnis S. Definition of the terms scheduled caste and scheduled tribes: a crisis of ambivalencec. In Pai Panandiker Va ed. The politics of backwardness: reservation policy in India. New Delhi. India. Centre for policy research. 1997.

19. Mohan V, Mathur P, Raj Deepa, Mohan D, Shukla DK, Geetha RM et al. Urban rural differences in prevalence of self reported diabetes in IndiaThe WHO-ICMR Indian risk factor surveillance. Diab Res Clin Prac. 2008; 80(1):159-168. Doi: 10.1016/j.diabres.2007

20.Hill J, Marcia N, Michael HF. Understanding the social factors that contribute to diabetes: A means to informing health care and social policies for the chronically ill. The Permanente Journal.2013;17(2):67-72. Doi: 10.7812/TPP/12-099

21. Okura Y, Urban LH, Mahoney DW et al. Agreement between self report questionnaire and medical record data was substantial for diabetes, hypertension, myocardial infarction and stroke but not for heart failure. J Clin Epidemiol 2004;57(10):1096-1103.

22.Subramaniam SV, Subramaniam MA, Selvaraj S et al. Are self reports of health and morbidities in developing countries misleading? Evidence from India. Soc Sci Med. 2009;68(2):260-265. Doi: 10.1016/j. socscimed.2008.10.017

23.DeoSS,Zantye A,Mokal R,Mithbawkar S,Rane S,Thakur K. To identify the risk factors for high prevalence of diabetes and impaired glucose tolerance in Indian rural population. Int J of Diab Devd Ctries. 2010;59:183. 